\title{
"We will do whatever it takes": Understanding Socioecological Level Influences on Hmong-American Adolescents and Parents' Perceptions of the Human Papillomavirus Vaccine
}

\author{
Serena Xiong ${ }^{1,2}$ (1) Maiyia Y. Kasouaher ${ }^{2} \cdot$ Bai Vue $^{2} \cdot$ Kathleen A. Culhane-Pera $^{3} \cdot$ Shannon L. Pergament ${ }^{2}$. \\ Jay Desai ${ }^{4,5} \cdot$ M. Beatriz Torres $^{6} \cdot$ Hee Yun Lee $^{7}$
}

Accepted: 15 June 2021 / Published online: 23 June 2021

(c) American Association for Cancer Education 2021

\begin{abstract}
Human papillomavirus (HPV) vaccination completion rates in Asian-American populations are substantially lower than most White Americans. Our objective was to identify the knowledge, perceptions, and decision-making processes about HPV vaccinations in the Hmong population, an Asian-American group with increased risks of HPV-related cancers. We conducted eight focus groups with Hmong adolescents $(n=12)$ and parents $(n=13)$ to learn about barriers, facilitators, and decision-making processes regarding general vaccinations and the HPV vaccine. The focus group results were analyzed using thematic analysis, informed by the socioecological model and asset lens. Findings showed that at the individual level, Hmong adolescents and parents had low HPV and HPV vaccine awareness levels (barrier) and strong desires to learn about HPV and the HPV vaccine (facilitator). Community-level barriers included salient narratives about traumatic experiences with vaccines and vaccine research, while facilitators included strong community connections. At the institutional level, barriers included structural constraints in health care settings, while facilitators included ease of obtaining vaccines at school-based clinics and provider authoritative decision-making. Additionally, a range of decision-making processes between parents, adolescents, and providers were present, with parents expressing a strong appeal to engage in more shared decision-making with providers. A linguistically and culturally specific HPV educational program for Hmong adolescents and parents could address the barriers and build on facilitators and assets to promote HPV vaccine uptake in this growing Asian-American community.
\end{abstract}

Keywords Human papillomavirus (HPV) $\cdot$ HPV vaccine $\cdot$ Hmong $\cdot$ Decision-making $\cdot$ CBPR

Serena Xiong

xiong455@umn.edu

1 School of Public Health, University of Minnesota, 1300 S 2nd Suite 300, Minneapolis, MN 55454, USA

2 Somali, Latino, and Hmong Partnership for Health and Wellness (SoLaHmo), Community-University Health Care Center (CUHCC), 2001 Bloomington Ave, Minneapolis, MN 55404, USA

3 Minnesota Community Care, 895 East 7th Street, St. Paul, MN 55106, USA

4 Minnesota Department of Health, Health Promotion and Chronic Disease Division, P.O. Box 64975, St. Paul, MN 55164, USA

5 HealthPartners Institute, P.O. Box 1524, Bloomington, MN 55440-1524, USA

6 Public Health Department, Mercyhurst University, 501 East 38th Street, Erie, PA 16546, USA

7 School of Social Work, University of Alabama, 1022 Little Hall, Box 870314, Tuscaloosa, AL 35487, USA

\section{Introduction}

High-risk human papillomavirus (HPV) types cause most cervical, penile, anal, and oropharyngeal cancers [1]. Hmong-Americans, an Asian ethnic community who arrived in the USA as a refugee group from Laos and Thailand after the Vietnam War in 1975, have high HPV-related cancer rates [2]. For example, Hmong-American women have some of the highest cervical cancer incidence $(36.3 / 100,000$ people) and mortality rates (10.5/100,000 people), four times greater than non-Hispanic White women [2, 3]. HPV vaccines prevent most cervical, penile, anal, and oropharyngeal cancers [4]. Despite this, HPV vaccine completion rates at a Minnesota community health center in 2016 for Hmong children ages 9-17 were low, with $32 \%$ in girls and $20 \%$ in boys, compared to the 2017 national rates of $47 \%$ in girls and 53\% in boys, respectively [5]. According to the 2020 American Community Survey, the Hmong ethnic group constitutes the 
largest Asian group in Minnesota at nearly 82,000 individuals, with more than $95 \%$ of Hmong Minnesotans residing in the urban Twin Cities core [6].

The reasons for low vaccination rates in Hmong adolescents are not well understood and are further complicated by a lack of studies and available survey data that disaggregate Asian-Americans within ethnicities [7]. Studies in other ethnic minority communities with HPV vaccination disparities point to a range of factors, including limited awareness, cultural or religious beliefs, limited health literacy, concerns about HPV being seen as related to the initiation of sexual activity, mistrust of healthcare providers, and provider behavior [8]. These findings reinforce the value of targeting health determinants beyond the individual level as a means to reduce health disparities, as many multilevel factors impact vaccination participation [9]. Numerous studies have highlighted the importance of the socioecological model (SEM), which describes how individuals' health behaviors are influenced by factors at multiple levels, including personal, interpersonal, institutional, community, and societal/public policy [10]. Interventions that target multiple levels of the socioecological model are better equipped for addressing the complexity of HPV vaccine uptake in minority populations $[9,11]$.

Intervention strategies may be more effective if they reflect community assets rather than deficits [12]. Community-based interventions, in particular, may incorporate protective factors within a community that influence, promote, and sustain health behavior changes. The use of community-based participatory research (CBPR) to engage community members as equal partners in the design and implementation of an intervention may result in more effective outcomes [13] and has demonstrated positive health outcomes, particularly in the Hmong community [14]. No research to date has explored factors shaping HPV vaccination uptake in the Hmong community and/or has taken into account assets within the SEM levels to address vaccination disparities. Qualitative data collection tools, such as interviews and focus groups, are widely used and accepted by the Hmong community [15] and may be appropriate for gathering information around this novel topic and research gap. Furthermore, prioritizing research that examines multilevel approaches while leveraging CBPR strategies can better inform future interventions to address these disparities. In this CBPR study, we aimed to examine Hmong adolescents and parents' perceptions (barriers, facilitators, and decisionmaking processes) about HPV vaccinations to address the gap around their low rates of HPV vaccination through a series of focus groups. Using the SEM framework with asset lens and CBPR approach, we aimed to identify Hmong adolescents and parents' perceptions (barriers, facilitators, and decision-making processes) about HPV vaccinations and identify multilevel (individual, community, institutional) factors that may influence HPV vaccination uptake in the Hmong community. We ultimately aim to build on the identified assets and address the identified challenges at each SEM level in order to increase HPV vaccination for Hmong adolescents.

\section{Methods}

\section{Community-Based Participatory Research (CBPR)}

This CBPR study equitably involved all partners in the research process. Partners were from the University Minnesota (UMN) School of Social Work, HealthPartners Institute (HPI)/Minnesota Department of Health (MDH), and Somali, Latino, and Hmong Partnership for Health and Wellness (SoLaHmo), a community-driven research organization that emphasizes an asset-based approach to maximize communities' inclusion in all phases of research. The CBPR team consisted of one UMN social work researcher, two Hmong bilingual UMN social work graduate students, one HPI/MDH researcher, three Hmong bilingual SoLaHmo community researchers, and three non-Hmong SoLaHmo researchers (including one health communications consultant). A community advisory board (CAB) comprised of seven Hmong community members and health professionals gave input on the study design and focus group recruitment strategies.

\section{Sample and Procedures}

In 2017, Hmong adolescent and parent dyads receiving care at a community health center in Minnesota were recruited to participate in age-specific focus groups. Hmong children and teens were invited to participate in the adolescent focus group sessions because of their potential role in decisionmaking [16]. A medical record query of the patient database identified 434 Hmong adolescents, ages 10-17 years, who had and had not completed the HPV vaccine series. Hmong community researchers on the CBPR team sent Hmong and English invitation letters to 150 families randomly selected from the query to participate in focus groups, including 75 who had and 75 who had not completed the HPV vaccine series. After several telephone contacts, 12 families (eleven 1:1 parent-child dyads and one 2:1 parent-child dyad) arrived (8\% response rate) to participate in the focus groups, most of whom had children who had not initiated the HPV vaccine series. Written informed consent and assent forms were collected from participants, and each participant was compensated $\$ 20$ for their time. 


\section{Data Collection}

Participating adolescents and parents completed a questionnaire about demographics, HPV, and the HPV vaccine. Adolescent and parent focus groups co-occurred in two separate rooms, given the potentially sensitive topic. Two bilingual community researchers trained in CBPR facilitated four focus groups with adolescents in English (two with boys and two with girls, $\mathrm{n}=12$ ) and four mixed-gender (e.g., motherfather, $n=13$ ) focus groups in Hmong with parents. Community researchers audiotaped and recorded observation notes of all focus group sessions. In addition, semi-structured focus group guides for adolescents and parents were created with input from the CAB members to explore participants' personal experiences with general vaccines, HPV vaccines, their reasons for and against getting vaccinated, and their vaccination decision-making processes. All focus groups lasted 60-90 min and were conducted at the community health center. The study was approved by the University of Minnesota Institutional Review Board (\#1612S01841).

\section{Data Analysis}

We ran descriptive statistics on the demographic and HPV survey responses. Community researchers translated and transcribed the parent focus groups from Hmong to English by listening to the audio recordings and transcribing in real time with Microsoft Word; verification of real-time translation and transcription was conducted by a second bilingual community researcher. The community-academic research team engaged in collaborative data analysis and interpretation for improved accuracy and culturally grounded insights. This approach can lead to more effective and sustainable interventions that resonate with communities while being grounded in science [17]. Along with the HPI/MDH researcher, three Hmong and three non-Hmong SoLaHmo team members coded the transcripts independently, engaged in a process to discuss and agree on codes, and then identified the main themes in the transcripts collaboratively. The participatory thematic analysis team used three levels of the SEM-individual, community, and institutional—and an asset lens to further interpret themes and codes. As part of this participatory thematic analysis, the team examined the codes and themes emerging from the data and further clustered them based on assets revealed by focus group participants. An "asset" referred to any potential factor, at any SEM level, that may facilitate increased HPV vaccination within the Hmong community.

\section{Results}

\section{Participants}

A total of 12 adolescents and 13 parents participated in eight focus groups. Adolescent participants were between ages 10 and 16 years old, born in the USA, bilingual, and most received free or reduced lunch. Parent participants were between ages 30 and 49 years old, and most were women, married, not born in the USA, had no formal education, spoke Hmong, and spoke little English. Generally, both Hmong adolescents and parents had low awareness levels regarding HPV or the HPV vaccine (Table 1).

\section{Individual Barriers and Facilitators}

Adolescent and parent participants described similar individual-level barriers to receiving vaccinations generally and the HPV vaccination specifically (Table 2). The most salient barrier was the low level of awareness regarding HPV and HPV vaccination, consistent with both groups' survey

Table 1 Study participant demographics $(\mathrm{N}=25)$

\begin{tabular}{|c|c|c|}
\hline Sociodemographic variables & $\begin{array}{l}\text { Adolescents } \\
(\mathrm{N}=12)\end{array}$ & $\begin{array}{l}\text { Parents } \\
(\mathrm{N}=13)\end{array}$ \\
\hline \multicolumn{3}{|l|}{ Adolescent age range } \\
\hline $10-13$ & 2 & - \\
\hline $14-16$ & 10 & - \\
\hline \multicolumn{3}{|l|}{ Parent age range } \\
\hline $30-49$ & - & 7 \\
\hline $50-69$ & - & 6 \\
\hline Gender: female & 6 & 8 \\
\hline \multicolumn{3}{|l|}{ Marital status } \\
\hline Single/separated/divorced & - & 3 \\
\hline Married & & 10 \\
\hline Insured with coverage & - & 11 \\
\hline Received free or reduced lunch & 11 & - \\
\hline \multicolumn{3}{|l|}{ Birth country } \\
\hline US & 7 & 0 \\
\hline Laos or Thailand & 5 & 13 \\
\hline \multicolumn{3}{|l|}{ Highest level of education } \\
\hline No formal education & - & 7 \\
\hline English language learner (ESL/ELL) & - & 5 \\
\hline Elementary school & 5 & 0 \\
\hline Some high school & 7 & 0 \\
\hline College graduate & - & 1 \\
\hline Speaks Hmong & 12 & 13 \\
\hline Speaks English & 12 & 3 \\
\hline Heard of the human papillomavirus (HPV) & 1 & 2 \\
\hline Heard of the HPV vaccine & 3 & 2 \\
\hline
\end{tabular}


Table 2 Adolescent themes, parent themes and assets organized by levels of the socioecological model (SEM)

\begin{tabular}{|c|c|c|c|}
\hline SEM levels & Adolescent themes & Parent themes & Assets \\
\hline \multirow[t]{3}{*}{$\begin{array}{l}\text { Individual (intrapersonal \& } \\
\text { interpersonal) }\end{array}$} & $\begin{array}{l}\text { Barriers } \\
\text { - Low level of awareness around } \\
\text { HPV and HPV vaccine } \\
\text { - Concerns about side effects } \\
\text { - Cost of vaccine }\end{array}$ & $\begin{array}{l}\text { Barriers } \\
\text { - Low level of awareness around } \\
\text { HPV and HPV vaccine } \\
\text { - Concerns about side effects } \\
\text { - Cost of vaccine } \\
\text { - Language barrier } \\
\text { - Concerns about the quality of } \\
\text { vaccines } \\
\text { - Concerns about vaccine research } \\
\text { - Historical harm of vaccines and } \\
\text { exploitation of vaccine research } \\
\text { - Concept of prevention }\end{array}$ & \\
\hline & $\begin{array}{l}\text { Facilitators } \\
\text { - Desire to learn more about HPV } \\
\text { and HPV vaccine }\end{array}$ & $\begin{array}{l}\text { Facilitators } \\
\text { - Desire to learn more about HPV } \\
\text { and HPV vaccine } \\
\text { - Trust in biomedicine \& heavy } \\
\text { reliance on providers } \\
\text { - Desire for healthy children }\end{array}$ & $\begin{array}{l}\text { - Desire to learn more about HPV } \\
\text { and HPV vaccine } \\
\text { - Trust in biomedicine \& heavy reli- } \\
\text { ance on providers } \\
\text { - Desire for healthy children }\end{array}$ \\
\hline & $\begin{array}{l}\text { Decision-making } \\
\text { - Children facilitate communica- } \\
\text { tion between parents and clinics/ } \\
\text { schools/doctors } \\
\text { - Knowledge-base of teens }\end{array}$ & $\begin{array}{l}\text { Decision-making } \\
\text { - Relying on children for com- } \\
\text { munication with others } \\
\text { - Knowledge-base of children } \\
\text { - Provider authoritative decision- } \\
\text { making }\end{array}$ & $\begin{array}{l}\text { - Desire for more shared decision- } \\
\text { making around health }\end{array}$ \\
\hline \multirow[t]{2}{*}{$\begin{array}{l}\text { Community (social circles/ } \\
\text { friends) }\end{array}$} & $\begin{array}{l}\text { Barriers } \\
\bullet \text { (None) }\end{array}$ & $\begin{array}{l}\text { Barriers } \\
\text { - Community narrative around } \\
\text { traumatic experiences with } \\
\text { vaccines }\end{array}$ & \\
\hline & $\begin{array}{l}\text { Facilitators } \\
\text { - Peer conversations }\end{array}$ & $\begin{array}{l}\text { Facilitators } \\
\text { - Family/community conversa- } \\
\text { tions }\end{array}$ & $\begin{array}{l}\text { - Peer/family/ } \\
\text { community conversations }\end{array}$ \\
\hline \multirow[t]{2}{*}{$\begin{array}{l}\text { Institutions (health care systems, } \\
\text { schools) }\end{array}$} & $\begin{array}{l}\text { Barriers } \\
\text { - HPV not required for school } \\
\text { - Communication methods with } \\
\text { children }\end{array}$ & $\begin{array}{l}\text { Barriers } \\
\text { - HPV not required for school } \\
\text { - Communication methods with } \\
\text { parents/kids } \\
\text { - Visit time constraints } \\
\text { - Parent passive engagement } \\
\text { in health discussions with the } \\
\text { provider } \\
\text { - Provider framing of health deci- } \\
\text { sions: fact vs. "opinion" }\end{array}$ & \\
\hline & $\begin{array}{l}\text { Facilitators } \\
\text { - Prompts for vaccines in sports/ } \\
\text { extra-curricular activity } \\
\text { - Education in health classes } \\
\text { - Education and vaccines in } \\
\text { school-based clinics }\end{array}$ & $\begin{array}{l}\text { Facilitators } \\
\text { - Provider authoritative decision- } \\
\text { making }\end{array}$ & $\begin{array}{l}\text { - Provider authoritative decision- } \\
\text { making } \\
\text { - Institutional levers (e.g., sports/ } \\
\text { extra-curricular activities, school- } \\
\text { based clinics) }\end{array}$ \\
\hline
\end{tabular}

responses $(\mathrm{N}=3$ adolescents and $\mathrm{N}=2$ parents have ever heard of the HPV vaccine). As a result, many focus group responses primarily centered on perceptions of and experiences with vaccinations in general. The two most common individual-level barriers to any type of vaccination were concerns about side effects and cost. Generally, adolescents and parents were concerned about the pain associated with any vaccination, if their insurance covered a vaccine, and if they could afford a vaccine at all.
Transportation isn't a big deal but cost is, because everything is money and I don't want to spend my money to be honest on [a] vaccine. (Adolescent, Focus Group \#1)

Parents also shared additional individual-level barriers to general vaccines. For example, for many parent participants, access to health information regarding vaccination was challenging because they did not read or speak English. 
Some parents were also concerned about the quality of vaccines in the USA. They believed that prior to immigration to the USA, the vaccines and medicines they received in their homelands or refugee camps were of poor quality and were concerned U.S. vaccinations might be the same. The parent participants who expressed these concerns also believed that vaccinations could cause shrinkage in some children's reproductive organs.

When we lived in Vinai (a Thailand refugee camp), when they say 'take your kids to get shots' then after that, there is no nice way to put it, but the sons, their private areas shrunk and you had to look for medicine to eat... and after that it became bigger again, so that's why some Hmong people are afraid [of vaccines]. (Parent, Focus Group \#1)

Furthermore, parent participants expressed concern that they had been part of vaccine research studies in refugee camps. Finally, parent participants shared a common sentiment about only seeking medical care for their children if they had symptoms of illness.

If my child doesn't have any sickness then why would I go? Why would they need a shot? What if they get the shot and they start having a fever? Then you would need to find medicine for them to eat also. (Parent, Focus Group \#3)

Adolescent and parent participants expressed a range of individual-level facilitators for getting vaccinations. For parent participants, facilitators included having trust in biomedicine and reliance on providers to make vaccination decisions for their children.

I do take them [my children] to go get shots. They are given shots according to what the doctor says. (Parent, Focus Group \#4)

After researchers shared information about the HPV vaccine with participants, both adolescent and parent participants expressed a desire to learn more about HPV and the HPV vaccine. Wanting healthy children, many parent participants affirmed they would initiate vaccinations if that meant protecting their children against sickness.

My husband and I are very supportive of keeping our kids healthy so we will do whatever it takes to keep our kids healthy. (Parent, Focus Group \#4)

\section{Community Barriers and Facilitators}

Adolescent participants did not report community-level barriers and tended to express their concerns at the individual level. Parent participants, however, shared community narratives around traumatic experiences with vaccines (e.g., shrinkage of reproductive organs) when they were refugees in Thailand. These narratives contributed to the communitylevel barrier for parents in accepting vaccinations for their children in the USA. Meanwhile, both adolescent and parent groups expressed that social connectedness was a community-level facilitator. They described how health information and education transpired and spread in conversations with peers, family members, and community members. In particular, parents reported that they rely on and trust health information when it comes from members within their own communities.

If you have a problem... go to others [in our community] who know a little bit about it. (Parent, Focus Group \#1)

\section{Institutional Barriers and Facilitators}

Both adolescent and parent participants described the absence of policies that require HPV vaccinations for school attendance as an institutional barrier. Parent participants also shared their frustration with the time constraints of a typical clinic visit, which limited their opportunity to engage in informative and educational discussions with their children's providers. During these visits, parents felt their role was passive, as they were only allowed to absorb the information given to them and were not given the opportunity to discuss the purpose of the vaccinations or additional vaccinations that their children may need. Finally, parent participants shared that they lacked confidence in decision-making about vaccinations for their children when providers framed health decisions as opinions (e.g., starting sentences as, "I think this vaccination will be best for your child...") rather than as a prescriptive fact (e.g., "I give this vaccination to your child to prevent serious diseases"). The use of neutral language by providers made it difficult for parents to understand what direction a decision should be made, as exemplified in the following quote:

So when they [providers] talk to parents, it doesn't seem like they are using what they learned. They are using what they think to tell us... they say, 'we think it should be good.' This means that they are using what they think to teach you. When it's like this, you already think that it is not good, but they keep on saying that it will be good. (Parent, Focus Group \#3)

Parents also identified providers' authoritative recommendations to get their children vaccinated as the most salient facilitator in obtaining the HPV vaccine.

...[the] vaccine is up to the doctor. If they say that we can get it, then we get it. (Parent, Focus Group \#4) 
Moreover, both parents and adolescent participants identified institutional-level facilitators at their schools-such as sports and extra-curricular activity prompts (e.g., annual check-ups or evaluations), health classes, and school-based clinics - as having the most significant potential to promote vaccination.

Since arriving on the US, (we know that) if your child isn't vaccinated, then schools will send letters to vaccinate our kids. We don't know what vaccines do, but at school they will send a letter telling you, you have this many vaccines left and you have to take your kids in to get vaccinated, if not then it will not be okay. So we have to bring our kids to get vaccinated. (Parent, Focus Group \#3)

\section{Decision-Making Processes}

Across focus groups, participants described a range of decision-making processes, both between adolescents and parents and between parents and providers. Several teens expressed they wanted a shared and collaborative decisionmaking process with their parents, while one adolescent reported making health decisions alone. Many parent participants described making the decisions for their children into their adolescence. This occurred despite parental linguistic barriers and a lack of access to health information. Some parent participants relied on their children to translate health materials and, in some cases, relying on them as medical interpreters when attending their clinic appointments.

We [parents] don't know much, and your children are the ones who goes to learn at school and it is the teachers telling them so they know, and you as parents if there's anything you don't know your children are the ones who translates for you. So this is a problem if child knows that this is something they should be going to, but us parents don't even know. Therefore, how do we force our children to go. Seems like they know more than us. If you were born and raise here then it would be okay, but you were not then you have to learn English, and therefore this is one of the problems. (Parent, Focus Group \#1)

However, from the parents' perspectives, having to trust and rely on their children for communication about health information was viewed as a one-directional interaction that left them vulnerable to their decision-making processes.

The dynamics of vaccination decision-making with providers were also raised. Many parent participants described playing a passive role with their children's providers, relying heavily on medical providers' judgment and decisions. At the same time, parents also expressed desires to play a more active and informed role in their children's vaccination decision-making process with more bidirectional conversations.

I prefer some explanation and little education about the vaccine shots and then, uh if it's appropriate at the time. Then yes, I would love the doctor to go ahead and vaccinate my child at the time that's required. (Parent, Focus Group \#2)

\section{Discussion}

To our knowledge, this is the first study to identify Hmong adolescents and parents' perceptions about the HPV vaccine. We identified barriers, facilitators, and decision-making processes in individual, community, and institutional levels that highlight influences on obtaining and not obtaining HPV vaccinations. Our study revealed low HPV and HPV vaccine awareness levels in the Hmong community, similar to other studies in cultural and ethnic minority communities [18, 19].

This original research found barriers for Hmong adolescents and parents at each SEM level. Individual-level and community-level barriers included concerns about side effects, costs, historical experiences with vaccines, parent literacy levels, and treatment (versus preventive) mindsets. These findings are consistent with other studies in minority populations [20-22] and demonstrate how language literacy, health literacy, and treatment mindset are challenges for delivering health care to Hmong patients. At the institutional level, adolescents and parents both faced barriers from clinics and school settings, including lack of policies to institute required HPV vaccinations, lack of support to facilitate parent-teen communications around vaccine decision-making, and provider procedural constraints. Providers who expressed vaccine recommendations as opinions (e.g., "I think") instead of presenting medical information as factual may also contribute to concerns and ambiguity in the parent decision-making process. Taken together, these barriers, coupled with the low rates of HPV vaccination in Hmong boys and girls, highlight an important opportunity for tailored multilevel programs to increase HPV knowledge and vaccination in this population.

We also identified facilitators and decision-making processes at each SEM level that can be leveraged to develop effective HPV vaccination programs for Hmong families. The individual eagerness expressed by adolescents and parents to learn more about HPV and the HPV vaccine indicates that HPV messages tailored to Hmong families are needed, particularly among Hmong parents who are willing to do anything to keep their children healthy. Hmong parents, furthermore, reported a strong reliance on biomedicine/medical providers and in conversations with members of their community networks. However, they also exhibited contradictory 
individual- and community-level narratives around trust in vaccinations - one about mistrust of vaccines (e.g., shrunken reproductive organ concerns) and one involving strong trust in doctors. This incongruity suggests that in parent-provider decision-making discussions, it may be pivotal to leverage the individual trust and respect in doctors themselves and counter the community mistrust in vaccines among Hmong parents. As established by numerous qualitative and quantitative studies, provider recommendation is strongly associated with the uptake of HPV vaccination [23, 24]. Therefore, incorporating providers and their interactions with parents in a multilevel HPV vaccination intervention is warranted in the Hmong community.

Incorporating school-based clinics and health education classes may also be a point of entry for a multilevel HPV vaccination intervention. Several review studies have found that school-based interventions significantly increase the uptake of the HPV vaccine in adolescents [25, 26]. One such prominent U.S. school-based HPV intervention includes the "Vaccinate Before You Graduate (VBYG)" program, which provides HPV vaccinations to 12th grade students at school-based clinics in Rhode Island at no out-of-pocket costs through a contract with a licensed wholesale drug distributor [27]. However, those developing such interventions need to consider the capacity of the government, school, and school-based clinics to implement such programs and whether specific culturally tailoring would be needed in heterogeneous school districts.

In the context of decision-making-between adolescents and parents, and between parents and providersmany of these processes were frequently one-directional, suggesting that the conversations about vaccinations happening in this community are not conducted in a shared decision-making fashion. However, the desire to incorporate more shared decision-making processes for all involved parties (adolescents, parents, and providers) is an asset. Multilevel interventions should incorporate a dyadic approach that involves both adolescents and parents with providers. Parent-teen interactions around health issues in adolescence, including HPV vaccination, have received considerable attention in recent research. Findings indicate that vaccine interventions engaging parents and their children result in significantly better health outcomes [28]. For example, a "dyadic" design recognizes the importance of parental knowledge in the acceptability of HPV vaccination. It capitalizes on both parents and children's potential to act as reciprocal health educators and co-contributors to health decisions. This approach is especially appropriate in the context of the Hmong community, where adolescents are already engaging with their parents in the process of health decisions as health messengers, interpreters, and even decision-makers [16]. As noted above, shared decision-making between providers and Hmong parents and adolescents, especially where parents' low literacy levels are a concern, is critical. Tapping into the knowledge and literacy base of Hmong adolescents can mediate this engagement between parents and providers. Finally, it is important to note that the provider's professional judgment (e.g., factual vs. opinion-like recommendation) may be a central influence in Hmong parents' decisions to get their children vaccinated for HPV.

\section{Applications for Community Education Within Public Health and Medicine}

Interventions for the Hmong community at each of the SEM level could leverage these identified facilitators, decision-making processes, and assets to address the individual and community challenges of language, literacy, and culture and institutional challenges of policies and procedures to increase HPV vaccination rates. Moving forward, individual-level interventions could include an interactive web-based educational platform; communitylevel interventions could include community health fairs and vaccination programs; institutional-level processes at schools could include health education and mandated HPV vaccines; and medical institutions could include and focus on shared decision-making between parents-adolescents and providers. Specifically, key processes that public health programs and medical practices could consider include creating and offering more culturally appropriate HPV and HPV vaccine educational messages; improving adolescent-parent communication about vaccinations; and increasing parent-adolescent-provider shared decisionmaking processes. Regarding public health programming, educational messages within the Hmong community should be transparent about the side effects of the HPV vaccine and emphasize the vaccine's safety and testing profile. The concerns raised by Hmong parents around literacy also suggest that communications to this community need to use low literacy, language concordant, and oral messaging modes to engage parents around HPV vaccination successfully. Within medical practices, providers should recognize that more visit time may be required with Hmong families to incorporate shared decision-making or clarify uses of neutral language (e.g., "I think"). Our current plans are to create, evaluate, and disseminate a culturally and linguistically appropriate interactive website about HPV disease and HPV vaccination for Hmong adolescents and parents. Overall, improved communication within the public health messaging and medical practice fronts in the Hmong community are necessary to facilitate more culturally responsive preventive care, including the uptake of vaccinations such as HPV and COVID-19. 


\section{Limitations}

The current study has several limitations. First, the low number of participants from both adolescent and parent focus groups may not have been sufficient to reach saturation so additional themes may not have emerged. A larger sample size might increase generalizability, present a greater diversity of views, and allow additional analyses by characteristics, such as parent-teen dyadic interactions, acculturation status, gender, age, and language. Furthermore, the low level of HPV and HPV vaccine awareness in our adolescent and parent focus groups may be an artifact of selection bias. Despite recruitment efforts aimed at 150 families, which included families whose teens had received HPV vaccines, only one family whose teen had received the HPV vaccine participated; hence, it is possible that those familiar with HPV vaccine declined to participate in the focus group sessions. Since recruitment for this study was challenging, future studies could expand beyond a clinic to include culturally resonant strategies in the Hmong community, such as recruiting through cultural events (e.g., Hmong New Year celebrations). Participants may have also felt inclined to share socially acceptable responses in the presence of their peers and researchers. However, this issue may have been minimal since awareness of HPV and the HPV vaccine was low in both groups. Finally, following CAB advice, the research team did not explicitly query participants on the connection between sex and HPV when participants did not mention it. This decision resulted in our team not exploring participants' views on the sexual nature of HPV transmission as a potential barrier to HPV vaccination [29]. Despite these limitations, our study still provides relevant information regarding the awareness and perceptions of the HPV vaccine in Hmong-Americans.

\section{Conclusion}

Hmong adolescents and parents have low levels of HPV and HPV vaccine knowledge, express concerns about side effects and costs, and face policy and procedural constraints as barriers to HPV vaccination. However, their desires to learn about HPV and the HPV vaccine, communicate with health care providers about the HPV vaccine, and be involved in shared decision-making are facilitators for HPV vaccinations. Multilevel interventions that address these challenges and capitalize on these identified facilitators, assets, and desired shared decision-making processes may be fruitful for encouraging HPV vaccine uptake in this Asian-American population.
Acknowledgements The authors would like to thank Tounhia Khang, Rebekah Pratt, Houa Vang, Naly Vang, and the community advisory board for their contributions to this study.

Author Contributions S.X. was involved in the implementation of the study, data collection, data analysis, and drafting and revising the manuscript. M.Y.K., B.V., K.A.C.P., S.P., and B.T. helped in implementing the study, collecting and analyzing the data, and editing the manuscript. J.D. helped in obtaining study approval, implementing the study, analyzing the data, and drafting and editing the manuscript. H.Y.L. conceived and designed the study and edited the manuscript. H.Y.L. is also the PI on the CDC/NCI grant funding for the project. All authors read and approved the final manuscript.

Funding This research project was funded by the Centers for Disease Control and Prevention (CDC) and the National Cancer Institute (NCI) to the last author (HYL) (Award number: 3U48DP005022-03S6 (Hee Yun Lee, PhD, MSW, P.I.)) and the National Institutes of Health's National Center for Advancing Translational Sciences (Award Number: TL1R002493 (Jayne Fulkerson, PhD, P.I.)) to support the first author's (SX) effort on analyzing the data, drafting, and revising the manuscript.

Data Availability The datasets supporting conclusions of this article are not available publicly due to containing sensitive information but are available from the corresponding author on reasonable request.

Code Availability Not applicable.

\section{Declarations}

Ethical Approval All procedures performed in the study were in accordance with the ethical standards of the University of Minnesota Institutional Review Board on Social and Behavioral Research (\#1612S01841).

Consent to Participate Informed consent and assent were obtained from all parents and adolescents included in the study.

Consent for Publication All participants signed informed assent and consent forms regarding publishing their data.

Conflict of Interest The authors declare no competing interests.

Disclaimer The content is solely the authors' responsibility and does not necessarily represent the official views of the National Institutes of Health's National Center for Advancing Translational Sciences.

\section{References}

1. Muñoz N, Bosch FX, De Sanjosé S et al (2003) Epidemiologic classification of human papillomavirus types associated with cervical cancer

2. Mills PK, Yang RC, Riordan D (2005) Cancer incidence in the Hmong in California, 1988-2000. Cancer 104:2969-2974. https:// doi.org/10.1002/cncr.21525

3. Yang RC, Mills PK, Riordan DG (2004) Cervical cancer among Hmong women in California, 1988 to 2000. Am J Prev Med 27:132-138. https://doi.org/10.1016/j.amepre.2004.04.003

4. Lu B, Kumar A, Castellsagué X, Giuliano AR (2011) Efficacy and safety of prophylactic vaccines against cervical HPV infection and 
diseases among women: a systematic review \& meta-analysis. BMC Infect Dis 11:13. https://doi.org/10.1186/1471-2334-11-13

5. Walker TY, Elam-Evans LD, Yankey D et al (2018) National, regional, state, and selected local area vaccination coverage among adolescents aged 13-17 years - United States, 2017. Morb Mortal Wkly Rep 67:909-917

6. United States Census Bureau (2020) ACS demographic and housing estimates. https://data.census.gov/cedsci/table?q=ACSDP 1Y2019. DP05+Minnesota\&g=0400000US27\&tid=ACSD P1Y2019.DP05\&hidePreview=true. Accessed 1 May 2020

7. Lor M (2018) Systematic review: health promotion and disease prevention among Hmong adults in the USA. J Racial Ethn Heal Disparities 5:638-661. https://doi.org/10.1007/ s40615-017-0410-9

8. Jeudin P, Liveright E, del Carmen MG, Perkins RB (2014) Race, ethnicity, and income factors impacting human papillomavirus vaccination rates. Clin Ther 36:24-37. https://doi.org/10.1016/j. clinthera.2013.11.001

9. Tiro JA, Pruitt SL, Bruce CM et al (2012) Multilevel correlates for human papillomavirus vaccination of adolescent girls attending safety net clinics. Vaccine 30:2368-2375. https://doi.org/10. 1016/j.vaccine.2011.11.031

10. McLeroy KR, Bibeau D, Steckler A, Glanz K (1988) An ecological perspective on health promotion programs. Health Educ Q 15:351-377. https://doi.org/10.1177/109019818801500401

11. Paskett ED, Krok-Schoen JL, Pennell ML et al (2016) Results of a multilevel intervention trial to increase human papillomavirus (HPV) vaccine uptake among adolescent girls. Cancer Epidemiol Biomarkers Prev 25:593-602. https://doi.org/10.1158/1055-9965. EPI-15-1243

12. Pan RJ, Littlefield D, Valladolid SG et al (2005) Building healthier communities for children and families: applying asset-based community development to community pediatrics. Pediatrics 115:1185-1187. https://doi.org/10.1542/peds.2004-2825Q

13. Minkler M (2000) Using participatory action research to build healthy communities. Public Health Rep 115:191. https://doi.org/ 10.1093/PHR/115.2.191

14. Kue J, Thorburn S, Keon KL (2014) Research challenges and lessons learned from conducting community-based research with the Hmong community. Health Promot Pract 16:411-418. https:// doi.org/10.1177/1524839914561515

15. Lor M, Gao C (2020) Hmong and Chinese qualitative research interview questions: assumptions and implications of applying the survey back translation method. Essent Role Lang Surv Res 181

16. Supple AJ, Small SA (2006) The influence of parental support, knowledge, and authoritative parenting on Hmong and European American adolescent development. J Fam Issues 27:1214-1232. https://doi.org/10.1177/0192513X06289063

17. Cashman SB, Adeky S, Allen AJ et al (2008) The power and the promise: working with communities to analyze data, interpret findings, and get to outcomes. Am J Public Health 98:1407-1417. https://doi.org/10.2105/AJPH.2007.113571

18. Adjei Boakye E, Tobo BB, Rojek RP et al (2017) Approaching a decade since HPV vaccine licensure: racial and gender disparities in knowledge and awareness of HPV and HPV vaccine. Hum
Vaccin Immunother 13:2713-2722. https://doi.org/10.1080/21645 515.2017.1363133

19. Reimer RA, Schommer JA, Houlihan AE, Gerrard M (2014) Ethnic and gender differences in HPV knowledge, awareness, and vaccine acceptability among White and Hispanic men and women. J Community Health 39:274-284

20. Glenn BA, Tsui J, Singhal R et al (2015) Factors associated with HPV awareness among mothers of low-income ethnic minority adolescent girls in Los Angeles. Vaccine 33:289-293. https://doi. org/10.1016/j.vaccine.2014.11.032

21. Abakporo U, Hussein A, Begun JW, Shippee T (2018) Knowledge, beliefs and attitudes of Somali men in Olmsted County, Minnesota, U.S., on the human papillomavirus vaccine and cervical cancer screening: January 17, 2015. J Immigr Minor Heal 20:1230-1235. https://doi.org/10.1007/s10903-017-0642-0

22. Pavlish CL, Noor S, Brandt J (2010) Somali immigrant women and the American health care system: discordant beliefs, divergent expectations, and silent worries. Soc Sci Med 71:353-361. https:// doi.org/10.1016/j.socscimed.2010.04.010

23. Holman DM, Benard V, Roland KB et al (2014) Barriers to human papillomavirus vaccination among US adolescents: a systematic review of the literature. JAMA Pediatr 168:76-82. https://doi.org/ 10.1001/jamapediatrics.2013.2752

24. Gilkey MB, Calo WA, Moss JL et al (2016) Provider communication and HPV vaccination: the impact of recommendation quality. Vaccine 34:1187-1192. https://doi.org/10.1016/j.vaccine.2016.01. 023

25. Ferrer HB, Trotter C, Hickman M, Audrey S (2014) Barriers and facilitators to HPV vaccination of young women in highincome countries: a qualitative systematic review and evidence synthesis. BMC Public Health 14:700. https://doi.org/10.1186/ 1471-2458-14-700

26. Gertig DM, Brotherton JML, Budd AC et al (2013) Impact of a population-based HPV vaccination program on cervical abnormalities: a data linkage study. BMC Med 11:227. https://doi.org/ 10.1186/1741-7015-11-227

27. Brotherton JML, Murray SL, Hall MA et al (2013) Human papillomavirus vaccine coverage among female Australian adolescents: success of the school-based approach. Med J Aust 199:614-617. https://doi.org/10.5694/mja13.10272

28. Winer RL, Gonzales AA, Noonan CJ, Buchwald DS (2016) A cluster-randomized trial to evaluate a mother-daughter dyadic educational intervention for increasing HPV vaccination coverage in American Indian girls. J Community Health 41:274-281. https://doi.org/10.1007/s10900-015-0093-2

29. Hansen CE, Credle M, Shapiro ED, Niccolai LM (2016) "It All Depends": a qualitative study of parents' views of human papillomavirus vaccine for their adolescents at ages 11-12 years. J Cancer Educ 31:147-152. https://doi.org/10.1007/s13187-014-0788-6

Publisher's Note Springer Nature remains neutral with regard to jurisdictional claims in published maps and institutional affiliations. 